\title{
A Surgical Approach to Giant Cell Tumor of Lower End of Tibia with Curettage and Reconstruction by Bone Grafting Harvested from Left Iliac Crest and K-wire Fixation: A Case Report
}

\author{
Pravakar Tripathy, Mahesh Chand Bansal, and Rahul Upadhyay
}

\section{ABSTRACT}

\begin{abstract}
Introduction: Giant cell tumor (GCT) is a distinctive lesion characterized by the proliferation of multinucleate giant cells in a stroma of mononuclear cells; it is generally seen in skeletally mature individuals. GCT is usually found in the long bones around the knee or in the distal radius but distal end of tibia, proximal humerus, vertebrae of young adults are unusual location. We report a case of GCT of the distal end of tibia, with a secondary aneurysmal bone cyst, in a 26-year-old female. Based on our review of the medical literature, it appears that the occurrence of a GCT along with a secondary aneurysmal bone cyst (ABC) in distal end of tibia is less typical with challenging task for full tumor resection and restoration of ankle function to normal.
\end{abstract}

Case Summary: 26 year old female presented with pain\&swelling over left ankle since last six month. Biopsy was suggestive of GCT with $A B C$ of lower third tibia. We managed this case with intralesional curettage using phenol and burr and bone graft harvested from left iliac crest for reconstruction of defect along with kwire fixation to achieve optimum anatomical restoration.

Conclusion: In cases of GCT, the management depends upon the various factors such as site, age, involvement of the bone, extent of bone involvement and whether there is articular involvement or not. Here Intra-articular GCT is managed with extended intralesional curettage with phenol. Bone graft plays a role of agent for reconstruction of the defect and kwire for anatomical reduction.

Keywords: Aneurysmal bone cyst, giant cell tumor, distal end tibia.
Submitted : July 4, 2021

Published : January 5, 2022

ISSN: 2593-8339

DOI: 10.24018 /ejmed.2022.4.1.971

P. Tripathy*

SMS Medical College Jaipur, India.

(pravakar.tripathy351@gmail.com)

M. C. Bansal

SMS Medical College Jaipur, India. R. Upadhyay

SMS Medical College Jaipur, India.

\section{INTRODUCTION}

Giant cell tumor (GCT) of bone is a neoplastic disease of bone (5\%) described by Sir Ashley cooper in 1818 [1]. Occur in middle age group (20-40 years) with female slightly more affected than male mostly around knee joint mostly solitary lesions; (1\%-2\% synchronously or metachronous multicentric). Typically, are benign (pulmonary metastases $3 \%$ of patients and mortality $15 \%$ ) [2].

Malignant GCT do occur in less than 5\% (primary or secondary). Primary being genetic and secondary related to previously irradiated cases [3]. Progressive pain initially by activity and later during rest. Pathological fractures may be the primary presentation in examination (10-30\%) cases [4], [5]. Xray are diagnostic. Shows eccentric epiphyseal and purely lytic. Soft tissue extension can be determined by MRI may reveal secondary aneurysmal bone cyst (20\%) [6], [7] . Histologically GCT are multinucleated giant cells (typically 40 to 60 nuclei per cell) in a sea of mononuclear stromal cells. Areas of storiform spindle cell formation, reactive bone formation, or foamy macrophage may be seen. Here we are reporting a case of GCT distal tibia left side of grade III which was managed surgically by wide resection and autologous bone grafting. Here our main purpose was anatomical restoration of ankle joint and preservation of function as much as possible.

\section{CASE REPORT}

A 26-year-old female presented on 20/4/2019 with pain and swelling over left ankle joint since last 6 month and had no history of trauma or physical effort and progressive worsening of the pain. On examination limping gait, visible swelling over left ankle medial aspect is seen with normal range of motion of ankle joint. on palpating tenderness over left medial aspect of ankle is present. On X-ray an extensive osteolytic lesion present at let ankle medial malleolus region, MRI revealed an expansile lytic sub-articular lesion at distal end of tibia measuring $36 \times 32 \times 37 \mathrm{~mm}$ with solid cystic component within suggestive GCT with Aneurysmal bone cyst. With surrounding inflammation. On the basis of above finding a bone biopsy was planned and performed and confirmatory diagnosis was established. Further treatment as intralesional curettage with phenol and electric burr and reconstruction by autologous bone graft harvested from left 
iliac crest and fixation by $\mathrm{k}$ wire was done. On follow up visit patient had no clinical abnormality full weight bearing was advised after 3 months approx. after removal of $\mathrm{k}$ wire. A fresh CT scan was performed showing adequate bone growth. Movement of ankle joint is around $80 \%$. Patient was then advised for vigorous physiotherapy and at further follow up every 6 monthly shows excellent movement and normal weight bearing at 2-year follow-up 20.05.2021.

\section{DisCUSSION}

As mostly benign nature generalized consensus is functional preserving surgery (Intralesional curettage and appropriate reconstruction) with aim to minimize chances of recurrence and maximize functional preservation. Various factors influencing the outcome of surgery are method of surgery, histologic type, tumor size, location and age of the patient and staging of tumor [8]. First enneking and later capanacci attempt to grade the tumor as grade I (well defined edge and cortical integrity) grade II (expanded cortex with well-defined edges) and grade III (non-defined edge with soft tissue invasion). For grade I \& II extensive curettage and reconstruction is advisable and for Grade III as high recurrence rate better to go with unblock resection and prosthesis insertion. Extended curettage can be done via chemicals (phenol), thermal (bone cement, electrocautery), cryotherapy (liquid nitrogen) or protein denaturation (argon beam coagulator), theoretically helps to kill any remaining tumor cells. Autograft bone, allograft bone, an artificial bone graft substitute, or methyl methacrylate bone cement can be used to fill the defect. Here we did extend Intralesional curettage with phenol and electric burr followed by autologous bone grafting harvested from left iliac crest and $\mathrm{k}$ wire fixation for fragment hold and anatomical reduction for better joint preservation and lesser complications. Patients diagnosed with GCT require long-term follow-up. Most of the complications occur by 3 years in the form of local recurrence or pulmonary metastasis [8]. The complications can be found after 20 years also. Chest Xray must be advised always to obtain stage of the lesion and rule out pulmonary metastasis.

As high recurrence of this tumor patient should be undergone repeated Xray follow up in every 6 months till 2 years then every year till 5 years of follow-up [10], [11]. Any abnormal Xray chest must be evaluated by CT. Local recurrence are presented in Xray as expanding lucency. On examination Soft-tissue changes may manifest as ossification or palpable mass, confirmed by MRI. Recurrent lesions are treated the same as for primary lesions. In cases of biopsy tumor is still benign, then repeat extended curettage should be done [12].

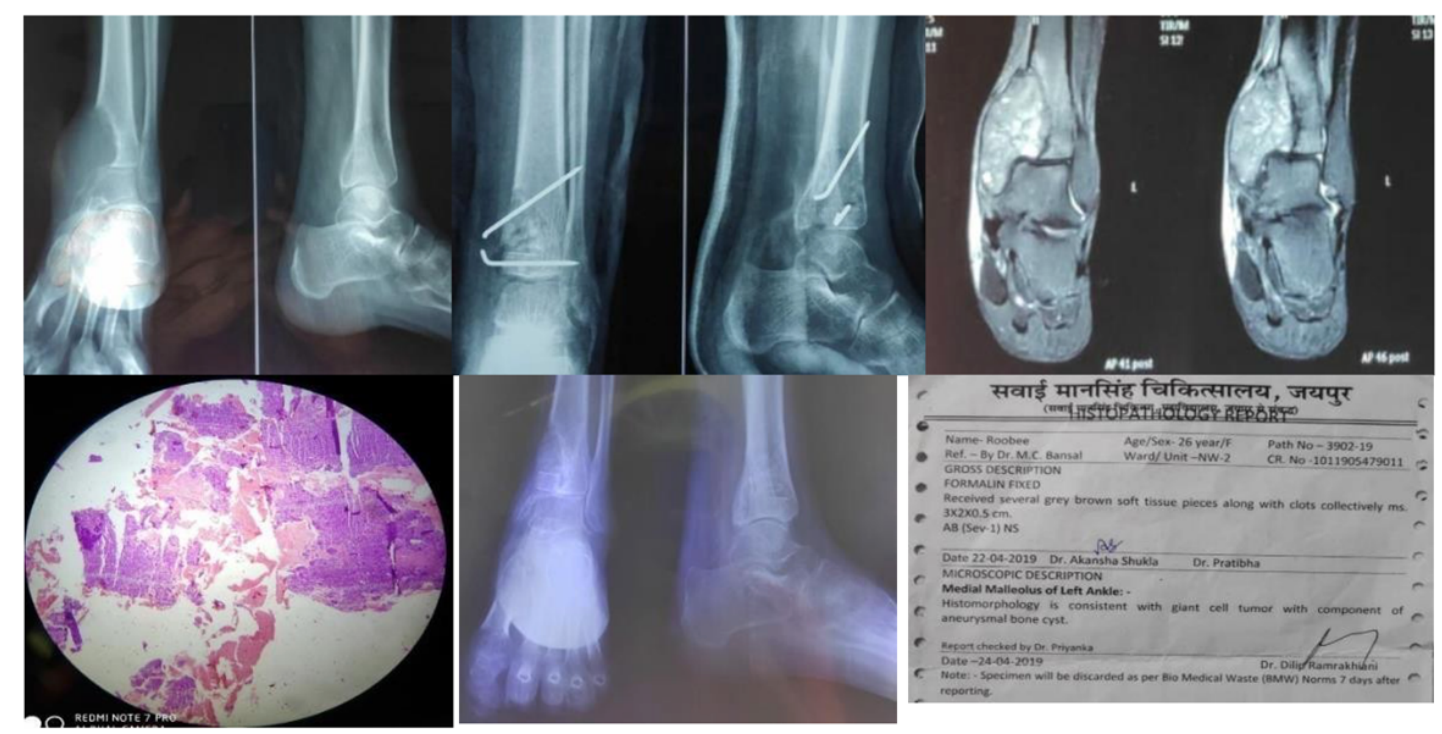

Figure (1) gct of lower end of tibia (2) immediate post of fixation after extensive Intralesional curettage and bone grafting and $k$ wire fixation (3) MRI scan of the lesion and its soft tissue extension (4) microscopic image of the gct lesion with ABC components (5) 2 year follow up after surgery (6) biopsy report of the lesion

\section{CONCLUSION}

The distal tibia (articular) involvement is a less common site for GCT. In present case we concluded that distal tibia GCT should be widely respected, fulfilling all the principles of oncological surgery and appropriate anatomical reconstruction for good functional outcome and prevent recurrence of the lesion.

\section{REFERENCES}

[1] Amanatullah DF, Clark TR, Lopez MJ, Borys D, Tamurian RM. Giant cell tumor of bone. Orthopedics. 2014; 37(2): 112-120.
[2] Knochentumoren A. Local recurrence of giant cell tumor of bone after intralesional treatment with and without adjuvant therapy. JBJS. 2008; 90(5): 1060-1067.

[3] Balke M, Campanacci L, Gebert C, Picci P, Gibbons M, Taylor R, et al. Bisphosphonate treatment of aggressive primary, recurrent and metastatic giant cell tumour of bone. BMC cancer. 2010; 10(1): 1-8.

[4] Boriani S, Bandiera S, Casadei R, Boriani L, Donthineni R, Gasbarrini A, Giant cell tumor of the mobile spine: a review of 49 cases. Spine. 2012; 37(1): E37-E45.

[5] Branstetter DG, Nelson SD, Manivel JC, Blay JY, Chawla S, Thomas $\mathrm{DM}$, et al. Denosumab induces tumor reduction and bone formation in patients with giant-cell tumor of bone. Clinical Cancer Research. 2012; 18(16): 4415-4424.

[6] Chan CM, Adler Z, Reith JD, Gibbs Jr CP. Risk factors for pulmonary metastases from giant cell tumor of bone. JBJS. 2015; 97(5): 420-428.

[7] Gao ZH, Yin JQ, Xie XB, Zou CY, Huang G, Shen JN. Local control of giant cell tumors of the long bone after aggressive curettage with and without bone cement. BMC Musculoskeletal Disorders. 2014; 15(1): 18 . 
[8] Gortzak Y, Kandel R, Deheshi B, Werier J, Turcotte RE, Ferguson PC, et al. The efficacy of chemical adjuvants on giant-cell tumour of bone: an in vitro study. The Journal of Bone and Joint Surgery. British Volume. 2010; 92(10): 1475-1479.

[9] Klenke FM, Wenger DE, Inwards CY, Rose PS, Sim FH. Giant cell tumor of bone: risk factors for recurrence. Clinical Orthopaedics and Related Research ${ }^{\circledR}$. 2011; 469(2): 591-599.

[10] Park SY, Lee MH, Lee JS, Song JS, Chung HW. Ossified soft tissue recurrence of giant cell tumor of the bone: four case reports with follow-up radiographs, CT, ultrasound, and MR images. Skeletal Radiology. 2014; 43(10): 1457-1463.

[11] Siddiqui MA, Seng C, Tan MH. Risk factors for recurrence of giant cell tumours of bone. Journal of Orthopaedic Surgery. 2014; 22(1): 108110.

[12] Skubitz KM. Giant cell tumor of bone: current treatment options. Current Treatment Options in Oncology. 2014; 15(3): 507-518. 